GABRIELA PENA CHAVES

\title{
Sistema Canabinóide e seu Possível \\ Papel em Processos de Neuroproteção e \\ Plasticidade: Estudos in vivo e in vitro
}

Dissertação de Mestrado apresentada ao Instituto de Ciências Biomédicas da Universidade de São Paulo, para obtenção de Título de Mestre em Ciências (Fisiologia Humana).

Área de Concentração: Fisiologia Humana

Orientadora: Profa. Dra. Andréa da Silva Torrão

São Paulo

2008 


\section{RESUMO}

CHAVES, GP. O Sistema Canabinóide e seu Possível Papel em Processos de Neuroproteção e Plasticidade: Estudos in vivo e in vitro. Dissertação - Instituto de Ciências Biomédicas da Universidade de São Paulo, São Paulo, 2008.

O sistema canabinóide parece exercer um papel modulador em vários processos neurobiológicos, incluindo processos de neuroproteção e plasticidade neuronal. Os objetivos desse trabalho foram avaliar, em um modelo in vivo, os efeitos de ablações retinianas unilaterais sobre a expressão do receptor canabinóide $\mathrm{CB}_{1}$ e de outras proteínas estruturais no tecto óptico de pintos de 2 semanas de vida e avaliar os efeitos do pré-tratamento com agonistas e antagonistas canabinóides in vitro em um modelo de culturas de células do tecto óptico expostas ao NMDA. Após diferentes períodos da ablação retininana (2-30 dias), os encéfalos foram submetidos às técnicas histoquímicas de TUNEL e Fluoro-Jade B para avaliar possíveis processos de morte celular por apoptose e de neurodegeneração, e imuno-histoquímica, immunoblotting e RT-PCR em tempo real para avaliar a expressão do receptor $\mathrm{CB}_{1}$. Além disso, os encéfalos foram avaliados quanto à expressão de uma série de proteínas estruturais. Culturas primárias de tecto óptico de embriões de pinto prétratadas com metanandamida e AM251 (agonista e antagonista canabinóides, respectivamente) e expostas ao agente tóxico NMDA, foram avaliadas quanto à viabilidade celular e fragmentação do DNA por citometria de fluxo e quanto à morfologia por imuno-citoquímica. O modelo de ablação retiniana parece não promover a morte celular no tecto óptico desaferentado, mas processos degenerativos foram observados em terminais axônicos da retina nas estruturas visuais. A ablação retiniana parece ter gerado um aumento da expressão da proteína $\mathrm{CB}_{1}$ no tecto óptico desaferentado, mas não dos níveis de RNAm. Além disso, proteínas associadas a axônios e a dendritos, em geral, aumentaram no tecto óptico após a ablação retiniana. $O$ tratamento das células em cultura com o agonista canabinóide diminuiu o número de células inviáveis e de DNAs fragmentados gerado pelo NMDA. Nossos resultados sugerem que o receptor $\mathrm{CB}_{1}$ parece apresentar uma localização pós-sináptica no tecto óptico, que o aumento de expressão observado seja um evento pós-transcricional e que essa expressão parece ser regulada negativamente pela aferência retiniana. Além disso, o aumento da expressão de proteínas estruturais sugere uma participação do receptor em processos de plasticidade. Os resultados com cultura de células sugerem um possível efeito neuroprotetor do sistema canabinóide em resposta aos efeitos tóxicos do NMDA. Os nossos dados são sugestivos de uma possível participação do sistema canabinóide em processos de plasticidade e de neuroproteção.

Palavras-chave: Receptores canabinóides. Neuroproteção. Plasticidade neuronal. Sistema Visual. Cultura Primária de Células. Sistema Canabinóide 


\begin{abstract}
CHAVES, GP. The Cannabinoid System and its Possible Role in Neuroprotection and Plasticity Processes: In vivo and in vitro Studies. Dissertation - Instituto de Ciências Biomédicas da Universidade de São Paulo, São Paulo, 2008.

The cannabinoid system seems to have a role in several neurobiological processes, including neuroprotection and neuronal plasticity. The objectives of this study were to assess on an in vivo model, the effects of unilateral retinal removal on the expression of cannabinoid receptor $\mathrm{CB}_{1}$ and other structural proteins in the optic tectum of 2 week old chicks, and evaluate the effects of pre-treatment with cannabinoid agonists and antagonists in an in vitro model of optic tectum cell cultures exposed to NMDA. In different periods after the retinal removal (2-30 days), the brains were subjected to the histochemical techniques TUNEL and Fluoro-Jade B to verify the possible occurrence of apoptosis and neurodegeneration, and immuno-histochemistry, immunoblotting and RT-PCR in real time to evaluate the expression of the receptor $\mathrm{CB}_{1}$. Moreover, the brains were evaluated as an expression of a series of structural proteins. Chick embryo's optic tectum primary cell culture pre-treated with methanandamide and AM251 (cannabinoid agonist and antagonist, respectively) and exposed to the toxic agent NMDA, were evaluated on the cell viability and DNA fragmentation by flow cytometry, and the morphology by immuno-cytochemistry. The model of retinal removal does not appear to promote cell death in the deafferented optic tectum, but degenerative processes were observed in axon terminals in visual structures. The retinal ablation seems to have generated an increase in the expression of protein $\mathrm{CB}_{1}$ in the deafferented optic tectum, but not the in levels of mRNA. Moreover, proteins associated with axons and dendritic processes in general increased in the optic tectum after retinal ablation. The treatment of the cells in culture with the cannabinoid agonist decreased the number of dead cells and fragmented DNAs generated by NMDA. Our results suggest that the $C_{1}$ receptor seems to have a post-synaptic localization in the optic tectum, that the observed increase of expression is a post-transcriptional event, and this expression seems to be negatively regulated by retinal inputs. Moreover, the increased expression of structural proteins suggest a participation of the $\mathrm{CB}_{1}$ receptor in plasticity processes. Our results in cell culture suggest a possible neuroprotective effect of the cannabinoid system in response to the toxic effects of NMDA. Our data are suggestive of a possible involvement of the cannabinoid system in processes of plasticity and neuroprotection.
\end{abstract}

Keywords: Cannabinoid receptors. Neuroprotection. Neuronal plasticityl. Visual System. Primary cell culture. Cannabinoid System. 


\section{INTRODUÇÃO}

\subsection{Aspectos Gerais}

A planta Cannabis sativa, popularmente conhecida como maconha, tem sido amplamente utilizada ao longo da história da humanidade com fins recreativos, devido a seus efeitos psicoativos, e terapêuticos, antiemético, anticonvulsivante, analgésico e estimulante do apetite. No entanto, a legalização para o uso terapêutico tem sido alvo de grandes discussões, dado seu potencial abuso e desenvolvimento de tolerância. O princípio psicoativo da maconha, o $\Delta^{9}$-tetrahidrocanabinol $\left(\Delta^{9}\right.$-THC), e os outros componentes canabinóides são moléculas lipofílicas que exercem seus efeitos centrais por se ligarem a receptores de membrana específicos. O sistema canabinóide endógeno parece desempenhar uma função modulatória em vários processos neurobiológicos, tais como funções motoras e cognitivas, antinocicepção, sono e comportamento alimentar, como sugerido pela distribuição anatômica de seus receptores e pelos efeitos farmacológicos bem conhecidos dos compostos relacionados aos canabinóides (AMERI, 1999; FERNANDÉZ-RUIZ et al., 2000; HOWLETT et al., 2002, 2004; PERTWEE, 1997, 2001; FRIDE, 2004). Vários estudos recentes também apontam os canabinóide endógenos como moduladores dos processos do desenvolvimento embrionário do encéfalo (BEGBIE et al., 2004; FERNANDÉZ-RUIZ et al., 2000; RAMOS et al., 2002; LEONELLI et al., 2005), propriedades neuroprotetoras em diversos modelos de neurotoxicidade (MATO et al., 2003; PARMENTIER- BATTEUR et al., 2002 ; GRUNDY et al., 2001, VAN DER STELT et al., 2001, 2005) e como mediador de processos de plasticidade em diversas estruturas do sistema nervoso central (ALVARES et al., 2006; TAGLIAFERRO et al., 2006; HASHIMOTODANI et al., 2007). 


\subsection{Sistema Canabinóide}

O sistema canabinóide endógeno, constituído pelos neuromediadores canabinóides, seus receptores e suas enzimas de síntese e degradação (AMERI, 1999; DE PETROCELLIS et al., 2004), teve sua identificação e caracterização relativamente recente.

\subsubsection{Canabinóides Endógenos}

Três compostos canabinóides endógenos já foram bem caracterizados até o momento, sendo o primeiro chamado de "anandamida" (etanol amida do ácido araquidônico), o segundo é o 2-araquidonoil-glicerol (2-AG), que é um éster também derivado do ácido araquidônico, e por fim, o terceiro é um éter do ácido araquidônico, o 2-araquidonoil-glicerol-éter. Existem diferenças entre as concentrações dos tipos de canabinóides endógenos no tecido nervoso, sendo a concentração de 2-AG aproximadamente 200 vezes maior que a de anandamida. Entretanto, a distribuição deles no encéfalo é bastante similar, pois ambos existem em maiores concentrações no tronco encefálico, estriado e hipocampo e em menores concentrações no córtex, diencéfalo e cerebelo. Curiosamente, parece não haver correlação entre as concentrações dos canabinóides endógenos e a distribuição de receptores canabinóides (FRIDE, 2002).

Esses dois canabinóides endógenos são derivados do ácido graxo $\omega 6-$ polinsaturado proveniente da dieta, o qual deriva de outros ácidos graxos essenciais. $\mathrm{O}$ precursor da anandamida é a $\mathrm{N}$-araquidonilfosfatidiletanolamina ( $\mathrm{N}$-ArPE) que é formada através da ação da NAT ( $\mathrm{N}$-aciltransferase), uma enzima cálcio-dependente. $\mathrm{N}$-ArPE é clivada pela $\mathrm{N}$-acilfosfatidiletanolamina (NAPE)-fosfolipase D específica (NAPE-PLD), originando a anandamida e ácido fosfatídico. A biossíntese do 2-AG é iniciada pelo $\mathrm{Ca}^{2+}$ intracellular que induz a formação de diacilglicerol (DAG) na membrana através da estimulação da via da fosfatidil-inositol-fosfolipase (PI-PLC). O 2-AG é o produto da DAG-liapase (DAGL) agindo na DAG (DI MARZO e MATIAS, 2005; BASAVARAJAPPA, 2007). 


\subsubsection{Receptores canabinóides}

Além dos canabinóides endógenos, compostos exógenos como, por exemplo, o princípio psicoativo da maconha, o $\Delta^{9}-\mathrm{THC}$, também agem nos receptores canabinóides. No entanto, existem diferenças farmacológicas entre os exo e os canabinóides endógenos no sistema nervoso central. Por exemplo, os efeitos farmacológicos da anandamida e do THC são bastante similares, mas a anandamida possui uma ação in vivo menos duradoura quando comparada com o canabinóide sintético derivado da planta, e isso ocorre devido à degradação enzimática rápida da anandamida (FRIDE, 2002).

Os efeitos dos compostos canabinóides dependem então em grande parte dos receptores canabinóides (CB). Dois receptores $C B$ foram clonados, um nomeado de $\mathrm{CB}_{1}$ (MATSUDA et al., 1990), também conhecido anteriormente como o subtipo do sistema nervoso central, mas que também é encontrado em outras estruturas, tais como baço e tonsila, e em menor quantidade na glândula adrenal, coração, útero, ovário, testículo e em nervos simpáticos. O outro receptor, nomeado de $\mathrm{CB}_{2}$ (MUNRO et al., 1993), que era previamente conhecido como o subtipo periférico, pois foi encontrado inicialmente apenas na periferia, em regiões marginais do baço, nas tonsilas e em células do sistema imune (AMERI, 1999). Contudo, os dois subtipos foram posteriormente encontrados no sistema nervoso central (FOWLER et al., 2001).

Os receptores $\mathrm{CB}$ pertencem à família de receptores acoplados à proteína $\mathrm{G} e$ a análise da sequência primária de aminoácidos revela a presença de sete domínios transmembrânicos, uma porção $\mathrm{N}$-terminal extracelular e uma porção C-terminal intracelular. O mecanismo de transdução dos sinais dos receptores CB envolve vias com a participação da proteína $\mathrm{G}_{\mathrm{i} / 0}$, inibindo a adenilil ciclase e ativando quinases, e caso dos receptores $\mathrm{CB}_{1}$, ainda modulando canais iônicos (DI MARZO et al., 1998; LUTZ, 2002; AMERI, 1999).

No contexto de nosso estudo, no qual utilizamos o tecido nervoso, vamos apenas mencionar daqui por diante os receptores $C_{1}$. Os receptores do tipo $C_{1}$ estão entre os receptores acoplados à proteína G mais abundantes no sistema nervoso e a sua distribuição foi bem caracterizada no encéfalo de ratos e de humanos. 
Em estudos com ligantes, as maiores densidades foram encontradas nos gânglios da base (substância negra, globo pálido, núcleo entopeduncular e estriado lateral) e no cerebelo. Altas densidades também foram encontradas nas células piramidais do hipocampo, no giro denteado e nas camadas I e IV do córtex. Densidades intermediárias de sítios de ligação foram encontradas no núcleo acumbens, e sítios esparsos ou ausentes no tronco encefálico, no bulbo e no hipotálamo (AMERI, 1999). Vários estudos que empregaram métodos de auto-radiografia, hibridização in situ e imuno-histoquímica também têm demonstrado a presença de receptores $\mathrm{CB}_{1} \mathrm{em}$ áreas do encéfalo de animais adultos, como no córtex cerebral, hipocampo, cerebelo e gânglios da base (GLASS et al., 1997; HERKENHAM et al., 1990; HERKENHAM et al., 1991a,b; MAILLEUX e VANDERHAEGHEN, 1992; TSOU et al., 1998). Alguns estudos têm também investigado a distribuição de receptores $\mathrm{CB}_{1}$ na retina de vertebrados adultos (BUCKLEY et al., 1998; STRAIKER et al., 1999 a,b; STRAIKER e SULLIVAN, 2003; YAZULLA et al., 1999). Estes estudos sugerem que a distribuição de receptores $\mathrm{CB}_{1}$ tanto no encéfalo como na retina é bem conservada entre as diferentes espécies de vertebrados.

É importante ressaltar que o receptor $\mathrm{CB}_{1}$ é bem conservado ao longo da evolução, pois $97 \%$ do $\mathrm{CB}_{1}$ de camundongo, $84 \%$ do $\mathrm{CB}_{1}$ de anfíbios e $72 \%$ do $\mathrm{CB}_{1}$ de peixes são idênticos à proteína do $\mathrm{CB}_{1}$ dos humanos (para revisão ver em LUTZ, 2002). Já para invertebrados a literatura apresenta controvérsias em relação à existência do receptor $\mathrm{CB}_{1}$. Lutz (2002) ressalta que até o momento o $\mathrm{CB}_{1}$ em invertebrados ainda não havia sido clonado, entretanto existiam evidências da ação farmacológica dos canabinóides e suas enzimas de degradação em alguns Filos, tais como Celenterados, Anelídeos, Moluscos e Equinodermos. Mais recentemente McPartiland e colaboradores (2006) descrevem a existência desses receptores na maioria dos animais com simetria bilateral, entretanto existem alguns dados curiosos como, por exemplo, a falta de receptor $\mathrm{CB}_{1}$ em insetos.

Investigações recentes mostram que o endocanabinóide anandamida, além de ser ligante dos receptores canabinóides $\mathrm{CB}_{1}$ e $\mathrm{CB}_{2}$, também é ligante de outros receptores, tais como o VR1 (receptor vanilóide 1), o TASK-1 (canal de potássio) e outros receptores não canabinóides acoplados à proteína $\mathrm{G}$ ainda não identificados 
(SZALLASI e DI MARZO, 2000; LUTZ, 2002; ROSS, 2003; VAN DER STELT e DI MARZO, 2005).

\subsubsection{Enzimas Relacionadas ao Sistema Canabinóide}

De modo geral, os canabinóides endógenos são liberados por neurônios póssinápticos após uma estimulação, e agem no receptor $\mathrm{CB}_{1}$ de neurônios présinápticos. Para que os canabinóides endógenos possam ser inativados, existe uma molécula transportadora de membrana, o transportador de anandamida da membrana celular (AMT), que a leva para dentro das células para que ocorra a degradação enzimática intracelular feita pela enzima ácido graxo amina hidroxilase (FAAH). O 2-AG também é captado pelo AMT e em seqüência sofre degradação enzimática intracelular pela monoacilglicerol lipase (MAGL) ou pela FAAH. De acordo com este mecanismo, altas concentrações de FAAH e AMT são encontradas nas áreas do encéfalo que possuem uma grande densidade de $\mathrm{CB}_{1}$, tais como $\mathrm{O}$ hipocampo, o cerebelo e o córtex cerebral (FRIDE, 2002; BASAVARAJAPPA, 2007).

\subsubsection{Mecanismos de Ação do Sistema Canabinóide}

Os receptores $\mathrm{CB}_{1}$ são abundantemente expressos em terminais axônicos, o que sugere a sua ação pré-sináptica na maioria das vezes. Como citado anteriormente, os canabinóides endógenos são liberados por neurônios pós-sinápticos e agem no receptor $\mathrm{CB}_{1}$ de neurônios pré-sinápticos. O resultado dessa ligação é uma redução da liberação de outros neurotransmissores, como o GABA e o glutamato. Logo após, os canabinóides endógenos são levados para o interior das células para serem degradados (FREUND et al., 2003; HASHIMOTODANI et al., 2007).

Quando os canabinóides endógenos se ligam aos receptores $\mathrm{CB}_{1}$ desencadeiam uma série de mecanismos intracelulares característicos dos receptores acoplados à proteína $\mathrm{G}_{\mathrm{i} / 0}$. A maioria dos autores descreve três eventos importantes (1) inibição da adenilil ciclase, levando a uma diminuição dos níveis de AMPc intracelular e de proteínas quinases $A$; (2) estimulação de sinalização de proteínas quinases ativadas por mitógeno (MAP quinase); (3) inibição de canais de 
$\mathrm{Ca}^{2+}$ dependentes de voltagem do tipo $\mathrm{N}$ e $\mathrm{P} / \mathrm{Q}$, e estimulação de canais de $\mathrm{K}^{+}$tipo $\mathrm{A}$ resultando numa diminuição do influxo de cálcio e num aumento do efluxo de potássio. Portanto, considerando também o fato de que o receptor $\mathrm{CB}_{1}$ é predominantemente expresso pré-sinapticamente, a ação dos canabinóides endógenos nessas vias de sinalização muito provavelmente contribuem para uma inibição da liberação de neurotransmissores em geral (LUTZ, 2002; DI MARZO, e al., 1998; DE PETROCELLIS et al., 2004). (Figura 1.1)

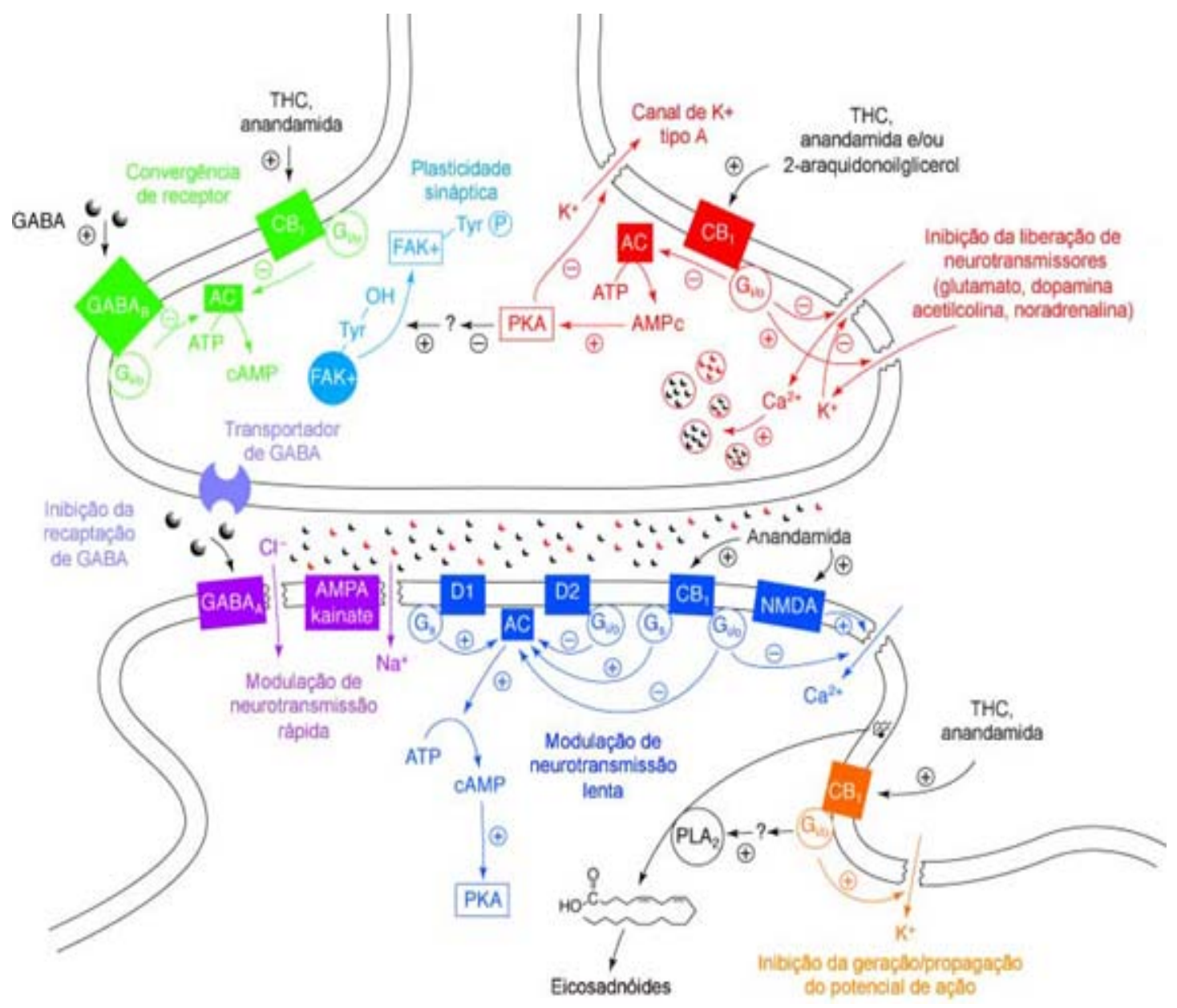

Figura 1.1: Mecanismos de ação dos canabinóides. No terminal pré-sináptico a anandamida e 2-AG ativam os receptors $\mathrm{CB}_{1}$ acoplados a proteína $\mathrm{G}$ modulando a permeabilidade da membrana neuronal aos íons $\mathrm{Ca}^{2+}$ and $\mathrm{K}^{+}$e a atividade da adenilato ciclase (AC) afetando assim a liberação ou a ação dos neurotransmissores ou ambas, e a neurotransmissão lenta e rápida. Uma vez liberados pela despolarização dos neurônios, os dois compostos, devido à sua lipofilia, podem se comportar como outros derivados do ácido araquidônico (AA), como sinais autócrinos e parácrinos agindo no próprio neurônio de origem ou em neurônios vizinhos ou em astrócitos. No hipocampo a inibição da $A C$ e posteriormente da proteína quinase $A(P K A)$ dependente de $A M P c$, também pode levar à modulação da plasticidade sináptica, por exemplo, através do aumento da fosforilação da tirosina e subsequente ativação da quinase de adesão focal + (FAK). Adaptado de DI MARZO et al., 1998. 


\subsubsection{Sistema Canabinóide, Neuroproteção e Neurodegeneração}

Recentemente o sistema canabinóide vem sendo apontado como um importante sistema em diversos modelos de neuroproteção. Muitos estudos apontam para a participação de endo e/ou exocanabinóide e para os receptores $\mathrm{CB}_{1}$ e $\mathrm{CB}_{2}$ nesses modelos. (PANIKASHVILI et al., 2001; MATO et al., 2003; PARMENTIERBATTEUR et al., 2002 ; GRUNDY et al., 2001; GILBERT et al., 2007 ; VAN DER STELT et al., 2001, 2005).

Os receptores $\mathrm{CB}_{1}$ também têm revelado um papel neuroprotetor em diversos modelos de neurotoxicidade, como hipóxia aguda, excitotoxicidade, e modelos de estresses oxidativos e traumáticos, tanto in vitro como in vivo. Em alguns estudos o efeito protetor parece estar relacionado com a inibição da liberação sináptica de glutamato, pois o glutamato extracelular é prejudicial aos neurônios em cultura. Além disso, nesses estudos os efeitos de neuroproteção foram atenuados pelo SR141716A, um antagonista do receptor $\mathrm{CB}_{1}$ (VAN DER STELT et al., 2002, PARMENTIERBATTEUR et al., 2002; JACKSON et al., 2005).

Panikashvili e colaboradores (2001) descrevem um possível envolvimento do canabinóide endógeno 2-AG na neuroproteção em estudos com camundongos, uma vez que esse canabinóide endógeno mostra um aumento significativo após lesão no encéfalo. Por outro lado, Hansen e colaboradores (2001) mostraram um aumento dos níveis do canabinóide endógeno anandamida, e não do 2-AG, em lesões no encéfalo de ratos.

De qualquer forma, os receptores $\mathrm{CB}_{1}$ parecem desempenhar um papel importante no processo de neuroproteção, e estudos anteriores sugerem que os efeitos protetores de canabinóide endógenos são mediados pela ativação dos receptores CB $_{1}$ (PANIKASHVILI et al., 2001, 2005; VELDHUIS et al., 2003). Entretanto, existem controvérsias sobre o assunto, pois alguns estudos mostram que a ativação dos receptores $\mathrm{CB}_{1}$ não possui efeito neuroprotetor em algumas culturas de células (NILSSON et al., 2003; MARSICANO et al., 2002).

Efeitos neuroprotetores dos canabinóides em cultura de neurônios corticais foram detectados por Kim et al. (2005) após indução de morte celular por oxidação 
com $\mathrm{FeCl}_{2}$ e com toxicidade por BSO (dl-butionina - $[\mathrm{S}, \mathrm{R}]$ - sulfoximina) e $\mathrm{H}_{2} \mathrm{O}_{2}$. Este efeito neuroprotetor foi atribuído aos mecanismos dependentes dos receptores $C_{1} B_{1} \mathrm{e}$ proteína quinase A. Outros estudos apontam que os canabinóides agem na redução ou bloqueio da liberação do cálcio intracelular em condições neurotóxicas e essa neuroproteção é baseada na diminuição da proteína quinase $A$ dependente de AMPc, mediada pelos receptores $\mathrm{CB}_{1}$ (ZHUANG et al., 2005).

Apesar de muitos trabalhos recentes defenderem os efeitos neuroprotetores para muitos canabinóides em diversos modelos de neurotoxicidade, os mecanismos exatos pelos quais este processo ocorre ainda não são muito conhecidos (MARSICANO et. al., 2002). Nesse contexto, é interessante mencionar que Khaspekov e colaboradores (2004) sugeriram que fatores neurotróficos podem ser importantes mediadores na neuroproteção por ativação dos receptores $\mathrm{CB}_{1}$ em modelos de excitotoxicidade.

\subsubsection{Sistema Canabinóide e Plasticidade}

Ultimamente os canabinóide endógenos e seus receptores específicos vêm sendo sugeridos como mediadores de processos de plasticidade em diversas estruturas do sistema nervoso central tais como estriado dorsal, núcleo acumbens, amígdala, hipocampo, cerebelo entre outros. Alguns mecanismos pelos quais o sistema canabinóide participa de eventos plásticos já foram descritos e, de maneira geral, envolvem a plasticidade a curto e a longo prazo. Entretanto, ainda não existe uma caracterização clara de todos esses eventos (para revisão ver CHEVALEYRE et al., 2006; HASHIMOTODANI et al., 2007).

A maioria dos estudos que relaciona o sistema canabinóide endógeno e plasticidade ressalta o fato destes neuromediadores serem retrógrados, com os receptores $\mathrm{CB}_{1}$ localizados pré-sinapticamente, mediando a liberação de outros neurotransmissores (CHAVALEYRE et al., 2006; HASHIMOTODANI et al., 2007). Sendo assim, é comum encontrarmos na literatura estudos sobre o sistema canabinóide e sua ação na plasticidade fisiológica, como por exemplo, em processos de memória e aprendizado (para revisão ver RIEDEL e DAVIES, 2005; ALVARES et al., 2006; FREUND et al., 2003; PIOMELLI, 2003; LAVIOLETTE e GRACE; 2006). 
Por exemplo, Álvares e colaboradores (2006) descrevem a participação do sistema canabinóide na consolidação da memória aversiva em ratos. Em linhas gerais, os autores discutem que a ativação dos receptores $\mathrm{CB}_{1}$ elicita LTP (potenciação a longo prazo) no hipocampo por inibir a liberação de GABA, facilitando a consolidação da memória aversiva. Um outro estudo mostra que a ativação dos receptores $\mathrm{CB}_{1}$ é importante para gerar LTD (depressão a longo prazo) em fibras trepadeiras do cerebelo, importantes para o aprendizado motor (VAN BEUGEN, et al., 2006).

Karanian e colaboradores (2005) descrevem a participação dos receptores $\mathrm{CB}_{1}$ na geração de importantes sinais para a manutenção das sinapses em hipocampo de ratos. Resumidamente, os canabinóides ativam vias relacionadas à sobrevivência das células $\mathrm{e}$ inibem os sinais que poderiam comprometer a integridade sináptica, envolvendo sistemas endógenos compensatórios.

No entanto, os estudos que tratam sobre plasticidade após lesões são mais raros. Assim, Ashton e colaboradores (2004) sugerem que os receptores $\mathrm{CB}_{1}$ podem contribuir no controle neuroquímico da plasticidade do sistema vestibular, porém, sem requerer mudanças na expressão protéica do receptor. Por meio de desaferentação unilateral do sistema vestibular esse estudo demonstrou que não existe alteração significativa na expressão do $\mathrm{CB}_{1}$ no lado desaferentado. Apesar disso o receptor $\mathrm{CB}_{1}$ pode estar envolvido em mecanismos de compensação vestibular por meio de LTP como já foi mostrado em outras regiões do encéfalo.

Tagliaferro e colaboradores (2006) por meio de tratamento crônico com WIN $55,212-2$, um agonista do receptor $\mathrm{CB}_{1}$, demonstram alterações em elementos do citoesqueleto e das densidades sinápticas em diversas regiões do encéfalo de ratos, sugerindo o envolvimento do sistema canabinóide em mecanismos de plasticidade, principalmente no que se refere à manutenção das sinapses, ressaltando a importância do estudo na contribuição de conhecimento sobre o papel do sistema canabinóide em diferentes modelos de lesão no sistema nervoso central.

\subsubsection{Sistema Canabinóide e Desenvolvimento}

Nos últimos anos, vários estudos sugeriram a participação do sistema canabinóide em processos de desenvolvimento do sistema nervoso. Esses estudos 
mostraram uma expressão precoce de uma quantidade considerável de receptores canabinóides durante o desenvolvimento do encéfalo, indicando um papel desse sistema em processos como a proliferação e migração neuronal, crescimento axonal e sinaptogênese (BEGBIE et al., 2004; FERNANDÉZ-RUIZ et al., 2000; LEONELLI et al., 2005; MATO et al., 2003; BERGHUIS et al., 2007).

De fato, uma expressão precoce de receptores $\mathrm{CB}_{1}$ tem sido caracterizada no encéfalo de pintos por hibridização in situ e imuno-histoquímica (BEGBIE et al., 2004; LEONELLI et al., 2005), de ratos por PCR, Northern blot, hibridização in situ, autoradiografia e imuno-histoquímica (BERRENDERO et al., 1998; BUCKLEY et al., 1998; MCLAUGHLIN e ABOOD, 1993; DESHMUKH et al., 2007) e no encéfalo de humanos por auto-radiografia e hibridização in situ (MATO et al., 2003; WANG et al., 2003). Também tem sido demonstrado que os canabinóides são capazes de modificar processos de maturação de sistemas específicos de neuromediadores, incluindo os sistemas opióide, dopaminérgico, serotonérgico e GABAérgico (FERNANDÉZ-RUIZ et al., 2000; MOROZOV e FREUND et al., 2003).

Alguns trabalhos sobre canabinóides e neuroproteção utilizam animais em desenvolvimento. Nilsson e colaboradores (2003) utilizaram cultura primária de telencéfalo de embriões de pintos para investigar a ação do receptor $\mathrm{CB}_{1}$ na prevenção da toxicidade do glutamato. Outro estudo mostra os efeitos neuroprotetores da anandamida usando lesões no encéfalo de ratos neonatos provocados por excitotoxicidade mediada por receptor AMPA-cainato (SHOUMAN et al., 2006).

É importante ressaltar que um estudo recente aponta para a existência de receptores $\mathrm{CB}_{1}$ no tecto óptico de pintos em desenvolvimento e em pintos pós-natais (LEONELLI, et al., 2005). Essa estrutura é bastante interessante para os estudos do sistema canabinóide em sistemas visuais de animais em desenvolvimento e também em animais adultos.

\subsection{Tecto Óptico}

O tecto visual de aves é um modelo bem estudado para uma variedade de questões fundamentais na neurobiologia, como o desenvolvimento, mapa da formação 
multimodal e plasticidade, conectividade e computação de estímulos visuais (LUKSCH, 2003). Além disso, é uma estrutura ampla e acessível tanto em animais adultos quanto nos animais em desenvolvimento (VENEGAS, 1984).

Os tectos ópticos de aves são muito desenvolvidos e possuem um alto grau de laminação. Existem duas nomenclaturas em uso para a laminação do tecto óptico de aves. Para o presente estudo iremos utilizar a nomenclatura numérica de Ramón y Cajal que diferenciou através de técnicas histológicas 15 camadas, com a numeração começando nas camadas superficiais (LUKSCH, 2003). Nessas camadas já foram identificados mais de 20 tipos de neurônios (LAVAIL e COWAN, 1971). (Figura 1.2)

O tecto óptico recebe diversas aferências com origem em diferentes partes do encéfalo. Entretanto as projeções da retina contralateral são predominantes e entram no tecto através das camadas superficiais. Projeções ispsilaterais transientes já foram demonstradas, porém são completamente eliminadas mais tarde no desenvolvimento por vários processos. Já as outras aferências do encéfalo não são confinadas às camadas superficiais, mas podem fazer conexões com todas as camadas do tecto óptico. As outras regiões do encéfalo que fazem projeções para o tecto óptico descritas na literatura são o sistema auditivo, núcleos do ístmo, telencéfalo, pré-tecto ipsilateral, entre outras (LUKSCH, 2003; WANG et al., 2006).

Diversos receptores tais como os colinérgicos e glutamatérgicos, entre outros (VENEGAS, 1984), e neurotransmissores como a glicina, o GABA, a acetilcolina e o glutamato (DIVAC et al., 1977) estão presentes no tecto óptico e foram estudados amplamente. Já recentemente, a literatura aponta para a existência de receptores canabinóides do tipo 1 em tecto óptico de Gallus gallus, desde E4 (quarto estágio embrionário) e também em animais adultos identificados com a técnica de imunohistoquímica (LEONELLI et al., 2005).

Em linhas gerais, essa estrutura se torna um bom modelo de estudo por três razões (1) recebe aferência direta e topográfica da retina para a superfície tectal; (2) é uma estrutura multi-estratificada com camadas facilmente reconhecíveis, o que facilita a avaliação de manipulações experimentais; e (3) há uma estrita separação entre as aferências e eferências visuais nos vários sistemas de projeções: enquanto as aferências retinianas terminam nas camadas superficiais, a maioria das eferências é 
derivada de projeções de neurônios das camadas mais profundas, fato este que facilita as análises da computação intratectal (LUKSCH, 2003).

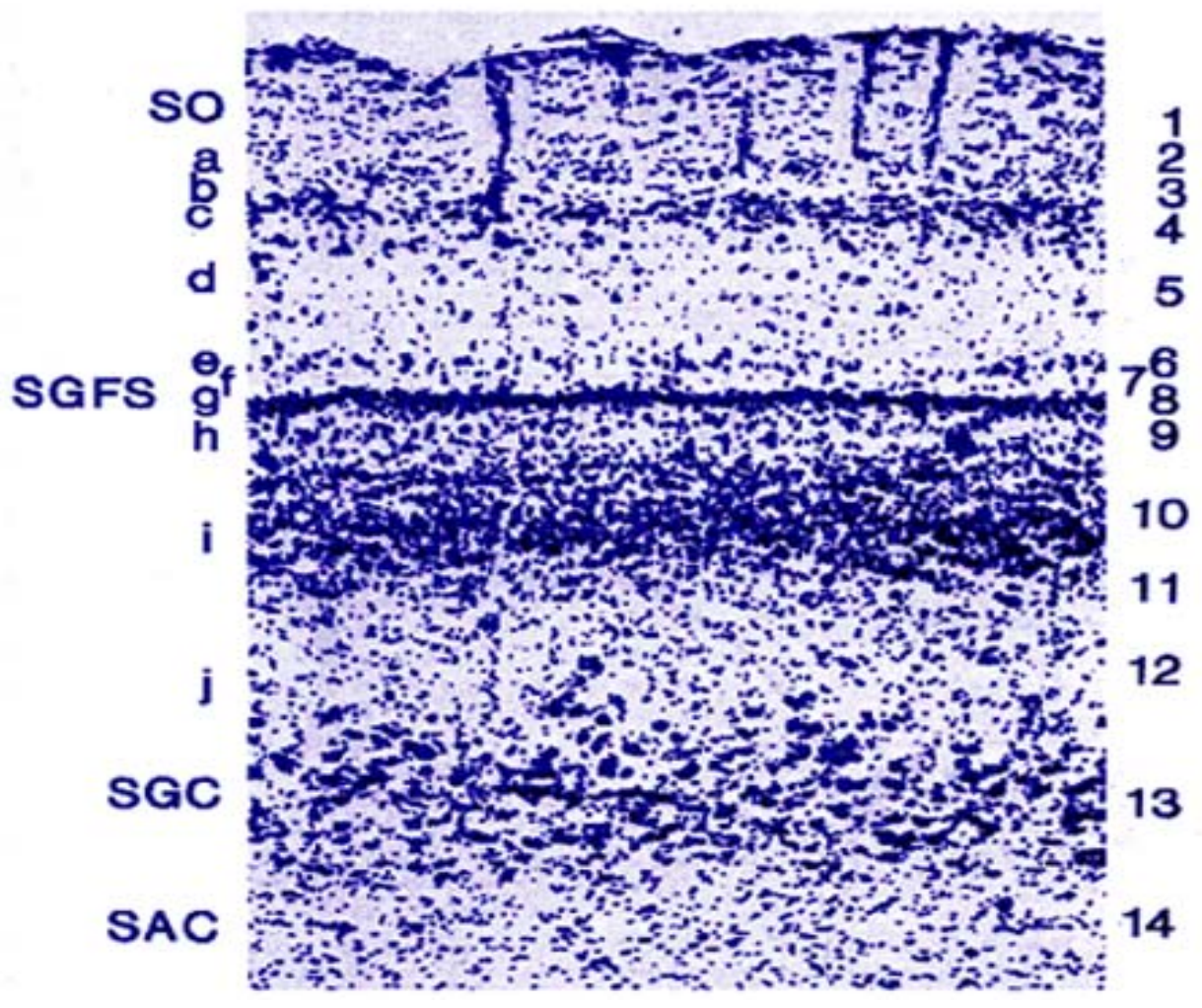

Figura 1.2: Imagem digital de corte coronal do tecto óptico de Gallus gallus corado com Giemsa. SGFS - substância cinzenta fibrosa superficial SGC/SAC - substância cinzenta central/substância branca central.Os números ao lado direito indicam a localização aproximada das camadas tectais de acordo com a nomenclatura de Ramón y Cajal.

\subsection{Processos neurodegenerativos, plasticidade e marcadores moleculares}

Vários métodos citológicos, histológicos e imuno-histoquímicos têm sido desenvolvidos com o intuito de avaliar morte celular, processos neurodegenerativos e plasticidade. Nesse contexto, citaremos nesta seção, uma série de moléculas que estão descritas na literatura e que têm sido utilizadas como marcadores desses 
eventos em vários modelos in vivo e in vitro de morte neuronal por agentes químicos, lesões ou doenças neurodegenerativas.

A morte celular programada por apoptose tem sido considerada um evento fundamental com função homeostática nos tecidos, já que a renovação tecidual depende de um balanço entre replicação e morte celular. Além disso, exerce um papel importante durante os processos de desenvolvimento. No sistema nervoso, especificamente, esse evento é fundamental para o refinamento dos circuitos neuronais durante o desenvolvimento e parece estar envolvido com a patogênese de algumas doenças neurodegenerativas (KALINICHENKO e MATVEEVA, 2007). O método de TUNEL (GAVRIELI et al., 1992) surgiu como uma útil ferramenta para avaliação de morte celular por apoptose em vários modelos tanto in vivo como in vitro. Esse método se baseia na marcação histoquímica da fragmentação do DNA, que identifica especificamente a transferência do grupo terminal 3'-OH mediada pela transferase do terminal desoxinucleotidil (TdT) do DNA para dUTP.

O método histoquímico Fluoro-Jade é utilizado para a detecção de neurônios em degeneração, marcando corpos celulares, dendritos, axônios e terminais axônicos e parece oferecer muitas vantagens em relação aos métodos histológicos convencionais. O mecanismo exato pelo qual o Fluoro-Jade marca neurônios em degeneração não é exatamente conhecido, mas parece que os neurônios presumivelmente expressam uma molécula fortemente básica apenas durante o processo degenerativo que apresenta uma alta afinidade pelo marcador ácido Fluoro-Jade (SCHMUED et al., 1997). Esse método foi posteriormente aprimorado com o uso do marcador Fluoro-Jade B, que apresentou uma maior afinidade pelos componentes em degeneração podendo ser utilizado em concentrações menores que o Fluoro-Jade e gerando marcações com maior definição (SCHMUED e HOPKINS, 2000).

A proliferação astrocítica em processos neurodegenerativos é um processo descrito há muito tempo e a marcação imuno-histoquímica da proteína glial fibrilar ácida (GFAP, marcadora de astrócitos) que evidencia a reação das células da glia durante processos lesivos, tem sido utilizada como ferramenta útil inclusive no diagnóstico clínico de neuropatologias (MCLENDON e BIGNER, 1994). 
Um marcador neuronal que tem sido bastante utilizado, é a proteína NeuN, uma proteína nuclear específica de neurônios que tem se mostrado um excelente marcador de neurônios no sistema nervoso central e periférico de vertebrados. Essa proteína aparece já durante o desenvolvimento em períodos que correspondem à saída dos neurônios do ciclo celular e/ou com o início da diferenciação neuronal (MULLEN et al., 1992). Esse marcador tem sido utilizado como forma de avaliação de perda neuronal já que aparentemente há uma diminuição dessa proteína em processos patológicos onde se observa morte neuronal (ÜNAL-ÇEVIK, et al., 2004).

Uma outra abordagem de caracterização de uma lesão pode ser a avaliação da atividade celular. Existem alguns genes imediatos, como, por exemplo, a família dos genes Egr, principalmente o Egr-1 que são extensivamente estudados no sistema nervoso central por duas razões: a ativação imediata do gene pode ser usada para traçar a ativação de vias neuronais; e o conhecimento de que os fatores de transcrição desses genes imediatos são induzidos pode fornecer a chave para a determinação do programa da expressão gênica que conduz aos efeitos a longo prazo da estimulação neuronal (BECKMANN e WILCE, 1997). Outros estudos avaliam a expressão de Egr após lesões, como, por exemplo, Torrão e Britto (2004) descrevem que a proteína nuclear Egr apresenta níveis mais baixos no tecto óptico após ablação retiniana em pintos.

No contexto da neuroproteção, as proteínas ligantes de cálcio tais como a calbindina, parvalbumina e calretinina, têm sido utilizadas como marcadores neuronais em estudos anatômicos e de desenvolvimento. Além disso, pelo possível envolvimento dessas proteínas no tamponamento de níveis intracelulares de cálcio, elas têm sido estudadas no contexto de danos neuronais gerados por eventos neurotóxicos e doenças neurodegenerativas, sendo sugerido que talvez elas tenham um papel protetor (HEIZMANN e BRAUN, 1992). Além disso, essas proteínas já foram bem caracterizadas no tecto óptico de pintos (PFEIFFER e BRITTO, 1997).

No contexto da plasticidade algumas ferramentas são frequentemente usadas para a verificação e avaliação de possíveis alterações morfológicas plásticas, como elementos do citoesqueleto e de densidades sinápticas (TAGLIAFERRO et al., 2006). Marcadores que evidenciam elementos estruturais presentes em axônios 
(PAN, marcador de neurofilamentos), dendritos (MAP-2, marcador de proteínas associadas a microtúbulo) e vesículas sinápticas (marcadores de proteínas associadas às vesículas como a sinaptofisina, por exemplo) são de extrema importância para a avaliação da plasticidade sináptica, principalmente no que se refere às possíveis modificações dos elementos estruturais de uma sinapse. 
quando comparada à cultura exposta apenas ao agente tóxico. Assim sendo, os autores concluíram que este modelo de cultura não é ideal para se verificar o papel neuroprotetor dos canabinóides. Este dado não está de acordo com nossos resultados obtidos com cultura de células, já que, aparentemente, a cultura de embriões de pintos, apenas com diferença na região coletada (o trabalho citado se refere ao telencéfalo e o nosso, ao mesencéfalo), parece ser um bom modelo para avaliar o papel neuroprotetor do sistema canabinóide.

É evidente que apesar dos resultados positivos obtidos com o presente estudo, a repetição dos experimentos para a obtenção de resultados mais conclusivos é necessária.

Além disso, tendo em conjunto todos os dados obtidos com nossos estudos in vitro devemos questionar a utilização do citômetro de fluxo para a avaliação de morte celular no nosso modelo experimental. Sabemos que este tipo de metodologia para linhagens imortalizadas de células gera resultados reprodutíveis e constantes, já que neste caso as células possuem o mesmo tamanho e, portanto, é mais fácil se estabelecer o padrão de leitura para o citômetro (os eventos contabilizados pelo aparelho estão relacionados ao tamanho das células) facilitando a "compreensão" dos eventos lidos pelo citômetro. Já em relação à cultura primária, como estão presentes diversos tipos celulares, de tamanhos diferentes, é muito difícil o estabelecimento de um padrão de leitura para o citômetro, podendo, muitas vezes gerar erros de leitura. Talvez a utilização de outros métodos, como, por exemplo, avaliar por métodos citoquímicos a morte por apoptose, como vimos em Chen e colaboradores (2005) que quantificaram as células marcadas com TUNEL; ou ainda realizar o mesmo tratamento descrito no presente estudo em linhagens de neurônio, como, por exemplo, a linhagem de neuroblastoma Neuro 2A. 


\section{REFERÊNCIAS BIBLIOGRÁFICAS}

ALVARES, L.O.; GENRO, B.P.; VAZ BREDA, R.; PEDROSO, M.F.; DA COSTA, J.C.; QUILLFELD,T J.A. AM251, a selective antagonist of the $\mathrm{CB}_{1}$ receptor, inhibits the induction of long-term potentiation and induces retrograde amnesia in rats. Brain Res., v. 1075, p. 60-67, 2006.

AMERI, A. The effects of cannabinoids on the brain. Prog. Neurobiol., v. 58, p. 315-348, 1999.

ASHTON, J.C.; APPLETON, I.; DARLINGTON, C. L.; SMITH, P. F. Immunohistochemical localization of cannabinoid $\mathrm{CB}_{1}$ receptor in inhibitory interneurons in the cerebellum. Cerebellum, v. 3, p. 222-226, 2004.

BASAVARAJAPPA, B.S. Critical enzymes involved in endocannabinoid metabolism. Protein. Pept. Lett., v. 14, p. 237-246, 2007.

BECKMANN, A. M.; WILCE, P.A. Egr transcription factors in the nervous system. Neurochem. Int., v. 31, p. 477-510,1997.

BEGBIE, J.; DOHERTY, P.; GRAHAM, A. Cannabinoid receptor $\mathrm{CB}_{1}$ expression follows neuronal differentiation in the early chick embryo. J. Anat., v. 205, p. 213-218, 2004.

BELMONTE, M.A.; SANTOS, M.F.; KIHARA, A.H; YAN, C.Y.; HAMASSAKI, D.E. LightInduced photoreceptor degeneration in the mouse involves activation of the small GTPase Rac1. Invest. Ophthalmol. Vis. Sci., v. 47, p. 1193-1200, 2006.

BENNETT, G.D.; MOSER, K.; CHAUDOIN, T.; ROSENQUIST, T.H. The expression of the NR1-subunit of the NMDA receptor during mouse and early chicken development. Reprod. Toxicol., v. 22, p. 536-541, 2006.

BERGHUIS, P.; RAJNICEK, A.M.; MOROZOV, Y.M.; ROSS, R.A.; MULDER, J.; URBÁN, G.M.; MONORY, K.; MARSICANO, G.; MATTEOLI, M.; CANTY, A.; IRVING, A.J.; KATONA, I.; YANAGAWA, Y.; RAKIC, P.; LUTZ, B.; MACKIE, K.; HARKANY, T.Hardwiring the brain: endocannabinoids shape neuronal connectivity. Science, v. 25, p. 1212-1216, 2007.

BERRENDERO, F.; GARCIA-GIL, L.; HERNANDEZ, M.L.; ROMERO, J.; CEBEIRA, M.; DE MIGUEL, R.; RAMOS, J.A.; FERNÁNDEZ-RUIZ, J.J. Localization of mRNA expression and activation of signal transduction mechanisms for cannabinoid receptor in rat brain during fetal development. Development, v. 125, p. 3179-3188, 1998.

\footnotetext{
* De acordo com:

ASSOCIAÇÃO BRASILEIRA DE NORMAS TÉCNICAS. NBR 6023: Informação e documentação: referências: elaboração. Rio de Janeiro, 2002.
} 
BISOGNO, T; DELTON-VANDENBROUCKE, I; MILONE, A; LAGARDE, M; DI MARZO, V. Biosynthesis and inactivation of $\mathrm{N}$-arachidonoylethanolamine (anandamide) and $\mathrm{N}$ docosahexaenoylethanolamine in bovine retina. Arch. Biochem. Biophys., v. 370, p. 300307, 1999.

BOBROV, M.Y.; LIZHIN, A.A.; ANDRIANOVA, E.L.; GRETSKAYA, N.M.; FRUMKINA, L.E.; KHASPEKOV, L.G.; BEZUGLOV, V.V. Antioxidant and neuroprotective properties of $\mathrm{N}$ arachidonoyldopamine. Neurosci. Lett., v. 431, p. 6-11, 2008.

BREIVOGEL, C.S.; WALKER, J.M.; HUANG, S.M.; ROY, M.B.; CHILDERS, S.R. Cannabinoid signaling in rat cerebellar granule cells: G-protein activation, inhibition of glutamate release and endogenous cannabinoids. Neuropharmacology, v. 47, p. 81-91, 2004.

BRITTO, L.R.; TORRAO, A.S.; HAMASSAKI-BRITTO, D.E.; MPODOZIS, J.; KEYSER, K.T.; LINDSTROM, J.M.; KARTEN, H.J. Effects of retinal lesions upon the distribution of nicotinic acetylcholine receptor subunits in the chick visual system. J.Comp. Neurol., v. 350, p. 473484, 1994a.

BRITTO, L.R.; GOBERSZTEJN, F.; KARTEN, H.J.; COX, K. Depletion and recovery of the calcium-binding proteins calbindin and parvalbumin in the pigeon optic tectum following retinal lesions. Brain Res., v. 661, p. 289-292, 1994 b.

BUCKLEY, N.E.; HANSSON, S., HARTA, G.; MEZEY, E. Expression of the $\mathrm{CB}_{1}$ and $\mathrm{CB} 2$ receptor messenger RNAs during embryonic development in the rat. Neuroscience, v. 82, p. 1131-1149, 1998.

BUSTIN, S.A. Absolute quantification of mRNA using real-time reverse transcription polymerase chain reaction assays. Mol. Endocrinol., v. 25, p. 169-193, 2000.

CARLSON, G.; WANG, Y.; ALGER, B. E. Endocannabinoids facilitate the induction of LTP in the hippocampus. Nat. Neurosci., v. 5, p. 723-724, 2002.

CHEN, J.; LEE, C.T.; ERRICO, S.; DENG, X.; CADET, J.L.; FREED, W.J. Protective effects of Delta(9)-tetrahydrocannabinol against N-methyl-d-aspartate-induced AF5 cell death. Brain Res. Mol. Brain Res., v. 134, p. 215-225, 2005.

CHEVALEYRE, V.; CASTILLO, P. E. Endocannabinoid-mediated metaplasticity in the hippocampus. Neuron, v. 43, p. 871-881, 2004.

CHEVALEYRE, V.; TAKAHASHI, K.A.; CASTILLO, P.E. Endocannabinoid-mediated synaptic plasticity in the CNS. Annu. Rev. Neurosci., v. 29, p. 37-76, 2006.

DE PETROCELLIS, L.; CASCIO, M.G.; DI MARZO, V. The endocannabinoid system: a general view and latest additions. Br. J. Pharmacol., v. 141, p. 765-774, 2004.

DESHMUKH, S.; ONOZUKA, K.; BENDER, K.J.; BENDER, V.A.; LUTZ, B.; MACKIE, K.; FELDMAN, D.E.; Postnatal development of cannabinoid receptor type 1 expression in rodent somatosensory cortex. Neuroscience, v. 145, p. 279-287, 2007. 
DI MARZO, V.; MELCK, D.; BISOGNO, T; DE PETROCELLIS, L. ocannabinoids: endogenous cannabinoid receptor ligands with neuromodulatory action. L.Trends Neurosci., v. 21, p. 521-528, 1998.

DI MARZO, V.; MATIAS, I. Endocannabinoid control of food intake and energy balance. Nat. Neurosci., v. 8, p. 585-589, 2005.

DIAZ DE BARBOZA, G.; BELTRAMINO, C.; BRITTO, L.; DE OLMOS, J.; DE OLMOS, S.; PFEIFFER, C. Effect of retinal ablation on the expression of calbindin D28k and GABA in the chick optic tectum. Eur. J. Histochem., v. 47, p. 365-372, 2003.

DIVAC, I.; FONNUM, F.; STORM-MATHISEN, J. High affinity uptake of glutamate in terminals of corticostrial axons. Nature, v. 266, p. 377-378, 1977.

DOWNER, E.J.; FOGARTY, M.P.; CAMPBELL, V.A. Tetrahydrocannabinol-induced neurotoxicity depends on $\mathrm{CB}_{1}$ receptor-mediated c-Jun $\mathrm{N}$-terminal kinase activation in cultured cortical neurons. Br. J. Pharmacol., v. 140, p. 547-557, 2003.

EL-REMESSY, A.B.; KHALIL, I.E.; MATRAGOON, S.; ABOU-MOHAMED, G.; TSAI, N.J.; ROON P..; CALDWELL, R.B.; CALDWELL, R.W.; GREEN, K.; LIOU, G.I. Neuroprotective effect of (-)Delta9-tetrahydrocannabinol and cannabidiol in N-methyl-D-aspartate-induced retinal neurotoxicity: involvement of peroxynitrite. Am. J. Pathol., v. 163, p. 1997-2008, 2003.

FAN, M.M.; RAYMOND, L.A. N-methyl-D-aspartate (NMDA) receptor function and excitotoxicity in Huntington's disease. Prog. Neurobiol., v. 81, p. 272-293, 2007.

FERNÁNDEZ-LÓPEZ, D.; PAZOS, M.R.; TOLÓN, R.M.; MORO, M.A.; ROMERO, J.; LIZASOAIN, I.; MARTÍNEZ-ORGADO, J. The Cannabinoid Agonist Win55212 Reduces Brain Damage in an In Vivo Model of Hypoxic-Ischemic Encephalopathy in Newborn Rats. Pediatr. Res., 2007.

FERNANDÉZ-RUIZ, J.; BERRENDERO, F.; HERNÁNDEZ, M.L.; RAMOS, J.A. The endogenous cannabinoid system and brain development. Trends Neurosci., v. 23, p. 14-20, 2000.

FOWLER, C.J.; NILSSON, O.; ANDERSSON, M.; DISNEY, G.; JACOBSSON, S.O.P.; TIGER, G. Pharmacological properties of cannabinoid receptors in the avian brain: similarity of rat and chicken cannabinoid1 receptor recognition sites and expression of cannabinoid2 receptor-like immunoreactivity in the embryonic chick brain. Pharmacol. Toxicol., v. 88, p. 213-222, 2001.

FREUND, T.F.; KATONA, I.; PIOMELLI, D. Role of endogenous cannabinoids in synaptic signaling. Physiol. Rev., v. 83, p. 1017-1066, 2003.

FRIDE, E. Endocannabinoids in the central nervous system - an overview. Prostaglandins Leukot Essent. Fatty. Acids, v. 66, p. 221-233, 2002.

FRIDE, E. The endocannabinoid-CB(1) receptor system in pre- and postnatal life. Eur. J. Pharmacol., v. 500, p. 289-297, 2004. 
GARCÍA-ARENCIBIA, M.; GONZÁLEZ, S.; DE LAGO, E.; RAMOS, J.A.; MECHOULAM, R.; FERNÁNDEZ-RUIZ, J. Evaluation of the neuroprotective effect of cannabinoids in a rat model of Parkinson's disease: importance of antioxidant and cannabinoid receptor-independent properties. Brain Res., v. 1134, p. 162-170, 2007.

GAVRIELI, Y.; SHERMAN, Y.; BEN-SASSON, S. A. Identification of programmed cell death in situ specific labeling of nuclear DNA fragmentation. Cell Biol., v. 119, p. 493-501, 1992.

GILBERT, G. L.; KIM, H. J.;; WAATAJA, J.J.; THAYER, S.A. Delta(9)-Tetrahydrocannabinol protects hippocampal neurons from excitotoxicity. Brain Res., v. 1128, p. 61-69, 2007.

GLASS, M.; FAULL, R.L.M.; DRAGUNOW, M. Cannabinoid receptors in the human brain: a detailed anatomical and quantitative autoradiographic study on the fetal, neonatal and adult human brain. Neuroscience, v. 77, p. 299-318, 1997.

GODINO MDEL, C.; TORRES, M.; SÁNCHEZ-PRIETO, J. CB ${ }_{1}$ receptors diminish both $\mathrm{Ca}(2+)$ influx and glutamate release through two different mechanisms active in distinct populations of cerebrocortical nerve terminals. J. Neurochem., v. 101, p. 1471-1482, 2007.

GRUNDY, R.I.; RABUFFETTI, M.; BELTRAMO, M. Cannabinoids and Neuroprotection. Mol. Neurobiol., v. 24, p. 29-51, 2001.

GUO, J.; IKEDA, S.R. Endocannabinoids modulate N-type calcium channels and G-proteincoupled inwardly rectifying potassium channels via $\mathrm{CB}_{1}$ cannabinoid receptors heterologously expressed in mammalian neurons. Mol. Pharmacol., v. 65, p. 665-674, 2004.

GUZMAN, M. Neurons on cannabinoids: dead or alive? Br. J. Pharmacol., v. 140, p. 439440, 2003.

HAMPSON, A.J.; GRIMALDI, M.; AXELROD, J.; WINK, D. Cannabidiol and (-)Delta9tetrahydrocannabinol are neuroprotective antioxidants. Proc. Natl. Acad. Sci. U S A, v. 95, p. 8268-8273, 1998.

HANSEN, H.H.; SCHMID, P.C.; BITTIGAU, P.; LASTRES-BECKER, I.; BERRENDERO, F.; MANZANARES, J.; IKONOMIDOU, C.; SCHMID, H.H.O.; FERNÁNDEZ-RUIZ, J.J.; HANSEN, H.S. Anandamide, but not 2-arachidonoylglycerol, accumulates during in vivo neurodegeneration. J. Neurochem., v. 78, p. 1415-1427, 2001.

HANSEN, H.H.; AZCOITIA, I.; PONS, S.; ROMERO, J.; GARCÍA-SEGURA, L.M.; RAMOS, J.A.; HANSEN, H.S.; FERNÁNDEZ-RUIZ, J. Blockade of cannabinoid CB(1) receptor function protects against in vivo disseminating brain damage following NMDA-induced excitotoxicity. J. Neurochem., v. 82, p. 154-158, 2002.

HASHIMOTODAN,I Y.; OHNO-SHOSAKU, T.; KANO, M. Endocannabinoids and Synaptic Function in the CNS. Neurocientist, v. 13, p. 127-137, 2007.

HEIZMANN, C.W.; BRAUN, K. Changes in $\mathrm{Ca}(2+)$-binding proteins in human neurodegenerative disorders. Trends Neurosci., v. 15, p. 259-264, 1992. 
HERKENHAM, M.; LYNN, A.B.; LITTLE, M.D.; JOHNSON, M.R.; MELVIN, L.S.; DE COSTA, B.R; RICE, K.C. Cannabinoid receptor localization in brain. Proc. Natl. Acad. Sci., v. 87, p. 1932-1936, 1990.

HERKENHAM, M.; LYNN, A.B.; DE COSTA, B.R.; RICHFIELD, E.K. Neuronal localization of cannabinoid receptors in basal ganglia of the rat. Brain Res,. v. 547, p. 267-274, 1991a.

HERKENHAM, M.; LYNN, A.B.; JOHNSON, M.R.; MELVIN, L.S.; DE COSTA, B.R.; RICE, K.C. Characterization and localization of cannabinoid receptors in the rat brain: a quantitative in vitro autoradiographic study. J. Neurosci., v. 11, p. 563-583, 1991 b.

HOWLETT, A.C.; BARTH, F.; BONNER, T.I.; CABRAL, G.; CASELLAS PDEVANE, W.A.; FELDER, C.C.; HERKENHAM, M.; MACKIE, K.; MARTIN, B.R.; MECHOULAM, R.; PERTWEE, R.G. International Union of Pharmacology. XXVII. Classification of Cannabinoid Receptors. Pharmacol. Rev., v. 54, p. 161-202, 2002.

HOWLETT, A.C.; BREIVOGEL, C.S.; CHILDERS, S.R.; DEADWYLER, S.A.; HAMPSON, R.E.; PORRINO, L.J. Cannabinoid physiology and pharmacology: 30 years of progress. Neuropharmacology, v. 47, p. 345-358, 2004.

JACKSON, S.J.; BAKER, D; CUZNER, M;L.; DIEMEL, L.T. Cannabinoid-mediated neuroprotection following interferon-gamma treatment in a three-dimensional mouse brain aggregate cell culture. Eur. J. Neurosci., v. 20, p. 2267-2275, 2004.

JACKSON, S.J.; DIEMEL, L.T.; PRYCE, G.; BAKER, D. Cannabinoids and neuroprotection in CNS inflammatory disease. J. Neuro.I Sci., v. 233, p. 21-25, 2005.

KALINICHENKO, S.G.; MATVEEVA, N.I.U. Morphological characteristic of apoptosis and its significance in neurogenesis. Morfologiya, v. 131, p. 16-28, 2007.

KANDEL, E. R.; SCHAWARTZ, J. H.; JESSELL, T. M. Princípio da Neurociência. Barueri: Manole, 2003.

KARANIAN, D.A.; BROWN, Q.B.; MAKRIYANNIS, A.; BAHR, B.A. Blocking cannabinoid activation of $F A K$ and ERK1/2 compromises synaptic integrity in hippocampus. Eur. J. Pharmacol., v. 508, p. 47-56, 2005.

KARANIAN, D.A.; BROWN, Q.B.; MAKRIYANNIS, A.; KOSTEN, T.A.; BAHR, B.A. Dual modulation of endocannabinoid transport and fatty acid amide hydrolase protects against excitotoxicity. J. Neurosci., v. 25, p. 7813-7820, 2006.

KHASPEKOV, L.G.; BRENZ VERCA, M.S.; FRUMKINA, L.E.; HERMANN, H.; MARSICANO, G.; LUTZ, B. Involvement of brain-derived neurotrophic factor in cannabinoid receptordependent protection against excitotoxicity. Eur. J. Neurosci., v. 19, p. 1691-1698, 2004.

KIM, S.H.; WON, S.J.; MAO, X.O.; JIN, K.; GREENBERG D.A. Involvement of protein kinase $A$ in cannabinoid receptor-mediated protection from oxidative neuronal injury. J. Pharmacol. Exp. Ther., v. 313, p. 88-94, 2005. 
KIM, S.H.; WON, S.J.; MAO, X.O.; JIN, K.; GREENBERG, D.A. Molecular mechanisms of cannabinoid protection from neuronal excitotoxicity. Mol. Pharmacol., v. 69, p. 691-696, 2006.

LAVAIL, J.H.; COWAN, W.M. The development of the chick optic tectum. I. Normal morphology and cytoarchitectonic development. Brain. Res., v. 28, p. 391-419, 1971.

LAVIOLETTE, S.R.; GRACE, A.A. Cannabinoids Potentiate Emotional Learning Plasticity in Neurons of the Medial Prefrontal Cortex through Basolateral Amygdala Inputs. J. Neurosci., v. 26, p. $6458-6468,2006$.

LEONELLI, M.; BRITTO, L.R.; CHAVES, G.P.; TORRAO, A.S. Developmental expression of cannabinoid receptors in the chick retinotectal system. Develop. Brain Res., v. 156, p. 176182, 2005.

LLANSOLA, M.; RODRIGO, R.; MONFORT, P.; MONTOLIU, C.; KOSENKO, E.; CAULI, O.; PIEDRAFITA, B.; EL MLILI, N.; FELIPO, V.. NMDA receptors in hyperammonemia and hepatic encephalopathy. Metab. Brain Dis., v. 22, p. 321-335, 2007.

LUKSCH, H. Cytoarchitecture of the avian optic tectum: neuronal substrate for cellular computation. Rev. Neurosci., v. 14, p. 85-106, 2003.

LUTZ, B, Molecular biology of cannabinoid receptors. Prostaglandins Leukot. Essent. Fatty Acids, v. 66, p. 123-142, 2002.

MACKIE, K.; DEVANE, W.A.; HILLE, B. Anandamide, an endogenous cannabinoid, inhibits calcium currents as a partial agonist in N18 neuroblastoma cells. Mol. Pharmacol., v. 44, p. 498-503, 1993.

MAILLEUX, P.; VANDERHAEGHEN, J.J. Distribution of the neuronal cannabinoid receptor in the adult rat brain: a comparative receptor binding radioautography and in situ hybridization histochemistry. Neuroscience, v. 48, p. 655-688, 1992.

MARSICANO, G.; MOOSMANN, B.; HERMANN, H.; LUTZ, B.; BEHL, C. Neuroprotective properties of cannabinoids against oxidative stress: role of the cannabinoid receptor $\mathrm{CB}_{1} . \mathbf{J}$. Neurochem., v. 80, p. 448-456, 2002.

MATO, S.; DEL OLMO, E.; PAZOS, A. Ontogenetic development of cannabinoid receptor expression and signal transduction functionality in the human brain. Eur. J. Neurosci., v. 17, p. 1747-1754, 2003.

MATSUDA, L.A.; LOLAIT, S.J.; BROWNSTEIN, M.J.; YOUNG, A.C.; BONNER, T.I. Structure of a cannabinoid receptor and functional expression of the cloned cDNA. Nature, v. 346, p. 561-564, 1990.

MCLAUGHLIN, C.R.; ABOOD M.E. Developmental expression of cannabinoid receptor mRNA. Dev. Brain Res., v. 76, p. 75-78, 1993.

MCLENDON, R.E.; BIGNER, D.D. Immunohistochemistry of the glial fibrillary acidic protein: basic and applied considerations. Brain. Pathol., v.4, p.221-228, 1994. 
MCPARTLAND, J.M.; AGRAVAL, J.; GLEESON, D.; HEASMAN, K.; GLASS, M. Cannabinoid receptors in invertebrates. J. Evol. Biol., v. 19, p. 366-373, 2006.

MECHOULAM, R.; SPATZ, M.; SHOHAMI, E., Endocannabinoids and neuroprotection. Sci. STKE., v. 129, 2002.

MECHOULAM, R. Discovery of endocannabinoids and some random thoughts on their possible roles in neuroprotection and aggression. Prostaglandins Leukot. Essent. Fatty Acids, v. 66, p. 93-99, 2002.

MOROZOV, Y.M.; FREUND, T.F. Post-natal development of type 1 cannabinoid receptor immunoreactivity in the rat hippocampus. Eur. J. Neurosci., v. 18, p. 1213-1222, 2003.

MULLEN, R.J.; BUCK, C.R.; SMITH, A. M. NeuN, a neuronal specific nuclear protein in vertebrates. Development, v. 116, p. 201-211, 1992.

MUNRO, S.; THOMAS, K.L.; ABU-SHAAR, M. Molecular characterization of a peripheral receptor for cannabinoids. Nature, v. 365, p. 61-65, 1993.

NILSSON, O.; JACOBSSON, S.O.; FOWLER, C.J. Cannabinoid CB $_{1}$ receptor activation does not prevent the toxicity of glutamate towards embryonic chick telencephalon primary cultures. Comp. Biochem. Physiol. C. Toxicol. Pharmacol., v. 136, p. 245-251, 2003.

NYÍRI, G.; CSERÉP, C.; SZABADITS, E.; MACKIE, K.; FREUND, T.F. CB ${ }_{1}$ cannabinoid receptors are enriched in the perisynaptic annulus and on preterminal segments of hippocampal GABAergic axons. Neuroscience, v. 136, p. 811-822, 2005.

PANIKASHVILI, D.; SIMEONIDOU, C.; BEN-SHABAT, S.; HANUS, L.; BREUER, A.; MECHOULAM, R.; SHOHAMI, E. An endogenous cannabinoid (2-AG) is neuroprotective after brain injury. Nature, v. 413 , p. 527-531, 2001.

PANIKASHVILI, D.; MECHOULAM, R.; BENI, S.M.; ALEXANDROVICH, A.; SHOHAMI, E. $\mathrm{CB}_{1}$ cannabinoid receptors are involved in neuroprotection via NF-kappa B inhibition. J. Cereb. Blood. Flow. Metab., v. 25, p. 477-484, 2005.

PANIKASHVILI, D.; SHEIN, N.A.; MECHOULAM, R.; TREMBOVLER, V.; KOHEN, R.; ALEXANDROVICH, A.; SHOHAMI, E. The endocannabinoid 2-AG protects the blood-brain barrier after closed head injury and inhibits mRNA expression of proinflammatory cytokines. Neurobiol. Dis., v. 22, p. 257-264, 2006.

PARMENTIER-BATTEUR, S.; JIN, K.; MAO, X.O.; XIE, L. GREENBERG D.A.; Increased severity of stroke in $\mathrm{CB}_{1}$ cannabinoid receptor Knock-out mice. J. Neurosci., v. 22, p. 97719775, 2002.

PEGORINI, S.; ZANI, A.; BRAIDA, D.; GUERINI-ROCCO, C.; SALA, M. Vanilloid VR1 receptor is involved in rimonabant-induced neuroprotection. Br. J. Pharmacol., v. 147, p. 552-559, 2006. 
PERTWEE, R.G. Pharmacology of cannabinoid $\mathrm{CB}_{1}$ and $\mathrm{CB}_{2}$ receptors. Pharmacol. Ther., v. 74 , p. 129-180, 1997.

PERTWEE, R.G. Cannabinoid receptors and pain. Prog. Neurobiol., v. 63, p. 569-611, 2001.

PFEIFFER, C. P.; BRITTO, L. R. Distribution of calcium-binding proteins in the chick visual system. Braz. J. Med. Biol. Res., v. 30, p. 1315-1318, 1997.

PIOMELLI, D. The molecular logic of endocannabinoid signaling. Nature Rev. Neurosci., v. 4, p. 873-884, 2003.

PIRES, R. S.; FERRO, E. S.; BRITTO, L. R. Expression of the AMPA-type glutamate receptor subunits in the chick optic tectum changes biphasically after retinal deafferentation. Brain Res., v. 810, p. 283-287, 1998.

PIRES, R. S.; REBOUÇAS, N. A.; DUVOISIN, R. M.; BRITTO, L. R. Retinal lesions induce differential changes in the expression of flip and flop isoforms of the glutamate receptor subunit GluR1 in the chick optic tectum. Brain Res. Mol. Brain Res., v. 76, p. 341-346, 2000.

PORCELLA, A.; CASELLAS, P.; GESSA, G.L.; PANI, L.Cannabinoid receptor $\mathrm{CB}_{1}$ mRNA is highly expressed in the rat ciliary body: implications for the antiglaucoma properties of marihuana. Brain. Res. Mol. Brain Res., v. 58, p. 240-245, 1998.

POZO DEVOTO, V. M.; CHAVEZ, J. C.; FISZER DE PLAZAS, S. Acute hypoxia and programmed cell death in developing CNS: Differential vulnerability of chick optic tectum layers. Neuroscience, v. 142, p. 645-653, 2006.

RAMÒN Y CAJAL, S. Histologie du système nerveux de l'homme et dês vertébrés. Paris: Manoile. 1911.

RAMOS, J.A.; DE MIGUEL, R.; CEBEIRA, M.; HERNANDEZ, M.; FERNANDEZ-RUIZ, J.J. Exposure to cannabinoids in the development of endogenous cannabinoid system. Neurotox. Res., v. 4, p. 363 - 372, 2002.

RIEDEL, G.; DAVIES, S.N. Cannabinoid function in learning, memory and plasticity. Handb. Exp. Pharmacol., v. 168, p. 445-477, 2005.

ROMERO, J.; WENGER, T.; DE MIGUEL, R.; RAMOS, J.A.; FERNÁNDEZ-RUIZ J.J. Cannabinoid receptor binding did not vary in several hypothalamic nuclei after hypothalamic deafferentation. Life Sci., v. 63, p .351-356, 1998.

ROMERO, J.; BERRENDERO, F.; PÉREZ-ROSADO, A.; MANZANARES, J.; ROJO, A.; FERNÁNDEZ-RUIZ, J.J.; DE YEBENES, J. G.; RAMOS, J.A. Unilateral 6-hydroxydopamine lesions of nigrostriatal dopaminergic neurons increased $C_{1}$ receptor mRNA levels in the caudate-putamen. Life Sci., v. 66, p. 485-494, 2000.

ROSS, R. Anandamide and vanilloid TRPV1 receptors. Br. J. Pharmacol., v. 140, p. 790801, 2003. 
SCHMUED, L. C.; HOPKINS, K. J. Fluoro-Jade B: a high affinity fluorescent marker for the localization of neuronal degeneration. Brain Res., v. 874, p. 123-130, 2000.

SCHMUED, L.C.; ALBERTSON, C.; SLIKKER, W.Jr. Fluoro-Jade: a novel fluorochrome for the sensitive and reliable histochemical localization of neuronal degeneration. Brain Res., $\mathrm{V}$. 751 , p. 37-46, 1997.

SHEN, M.; THAYER, S.A. Cannabinoid receptor agonists protect cultured rat hippocampal neurons from excitotoxicity. Mol. Pharmacol., v. 54, p. 459-462, 1998.

SHIMIZU, T.; COX, K.; KARTEN, H.J.; BRITTO, L.R. Cholera toxin mapping of retinal projections in pigeons (Columbia livia), with emphasis on retinohypothalamic connections. Vis. Neurosci., v. 11, p. 441-446, 1994.

SHOUMAN, B.; FONTAINE, R.H.; BAUD, O.; SCHWENDIMANN, L.; KELLER, M.; SPEDDING, M.; LELIEVRE, V.; GRESSENS, P. Endocannabinoids potently protect the newborn brain against AMPA-kainate receptor-mediated excitotoxic damage. $\mathrm{Br}$. J. Pharmacol., v. 148, p. 442-451, 2006.

SOLER-LLAVINA, G.J.; SABATINI, B.L.; Synapse-specific plasticity and compartmentalized signaling in cerebellar stellate cells. Nat. Neurosci., v. 9, p. 798-806, 2006.

SOMMER, C.; SCHOMACHER, M.; BERGER, C.; KUHNERT, K.; MÜLLER, H.D.; SCHWAB, S.; SCHÄBITZ, W.R. Neuroprotective cannabinoid receptor antagonist SR141716A prevents downregulation of excitotoxic NMDA receptors in the ischemic penumbra. Acta Neuropathol, v. 112 , p. $277-286,2006$.

STRAIKER, A.; STELLA, N.; PIOMELLI, D.; MACKIE, K.; KARTEN, H.J.; MAGUIRE, G. Cannabinoid $\mathrm{CB}_{1}$ receptors and ligands in vertebrate retina: localization and function of an endogenous signaling system. Proc. Natl. Acad. Sci., v. 96, p. 14565-14570, 1999 a.

STRAIKER, A.J.; MAGUIRE, G.; MACKIE, K.; LINDSEY, J. Localization of cannabinoid CB $_{1}$ receptors in the human anterior eye and retina. Invest. Ophthalmol. Vis. Sci., v. 40, p. 24422448, 1999 b.

STRAIKER, A.; SULLIVAN, J.M. Cannabinoid receptor activation differentially modulates ion channels in photoreceptors of the tiger salamander J. Neurophysiol., v. 89, p. 2647-2654, 2003.

SZALLASI, A.; DI MARZO, V. New perspectives on enigmatic vanilloid receptors. Trends Neurosci., v. 23, p. 491-497, 2000.

TAGLIAFERRO, P.; JAVIER RAMOS, A.; ONAIVI, E.S.; EVRARD, S.G.; LUJILDE, J.; BRUSCO, A.R. Neuronal cytoskeleton and synaptic densities are altered after a chronic treatment with the cannabinoid receptor agonist WIN 55,212-2. Brain Res., v. 1085, p. 163176, 2006.

TAKAHASHI, K.A.; CASTILLO, P.E. The $\mathrm{CB}_{1}$ cannabinoid receptor mediates glutamatergic synaptic suppression in the hippocampus. Neuroscience, v. 139, p. 795-802, 2006. 
TANG, Y.Z. Carr CE.Development of N-methyl-D-aspartate receptor subunits in avian auditory brainstem. J. Comp. Neurol., v. 502, p. 400-413, 2007.

TORRAO, A. S.; BRITTO, L. R. Increased expression of nitric oxide synthase in visual structures of the chick brain after retinal removal. J. Neurosci. Res., v. 78 p. 123-131, 2004.

TSOU, K.; BROWN, S.; SANUDO-PENA, M.C.; MACKIE, K.; WALKER, J.M. Immunohistochemical distribution of cannabinoid $\mathrm{CB}_{1}$ receptors in the rat central nervous system. Neuroscience, v. 83, p. 393-411, 1998.

TZOUNOPOULOS, T.; RUBIO, M.E.; KEEN, J.E.; TRUSSELL, L.O. Coactivation of pre- and postsynaptic signaling mechanisms determines cell-specific spike-timing-dependent plasticity. Neuron, v. 54, p. 291-301, 2007.

ULLRICH, O.; MERKER, K.; TIMM, J.; TAUBER, S. Immune control by endocannabinoids New mechanisms of neuroprotection? J. Neuroimmunol., v. 184, p. 127-135, 2007.

ÜNAL-CEVIK, I.; KILINC, M.; GURSOY-OZDEMIR, Y.; GURER, G.; DALKARA, T, Loss of NeuN immunoreactivity after cerebral ischemia does not indicate neuronal cell loss: a cautionary note. Brain Res., v. 1015, p. 169-174, 2004.

UNZICKER, C.; ERBERICH, H.; MOLDRICH, G.; WOLDT, H.; BULLA, J.; MECHOULAM, R.; EHRENREICH, H.; SIRÉN, AL. Hippocampal cannabinoid-1 receptor upregulation upon endothelin-B receptor deficiency: a neuroprotective substitution effect?. Neurochem. Res., v. 30, p. 1305-1309, 2005.

VAN BEUGEN, B.J.; NAGARAJA, R.Y.; HANSEL, C. Climbing fiber-evoked endocannabinoid signaling heterosynaptically suppresses presynaptic cerebellar long-term potentiation. J. Neurosci., v. 26, p. 8289-8294, 2006.

VAN DER STELT, M.; VELDHUIS, W.B.; VAN HAAFTEN, G.W,; FEZZA, F.; BISOGNO, T.; BAR, P.R.; VELDINK, G.A.; VLIEGENTHART, J.F.; DI MARZO, V.; NICOLAY, K. Exogenous anandamide protects rat brain against acute neuronal injury in vivo. J. Neurosci., v. 21, p. 8765-8771, 2001.

VAN DER STELT, M.; VELDHUIS, W.B.; MACCARRONE, M.; BAR, P.R.; NICOLAY, K.; VELDINK, G.A.; DI MARZO, V.; VLIEGENTHART, J.F. Acute neuronal injury, excitotoxicity, and the endocannabinoid system. Mol. Neurobiol., v. 26, p. 317-346, 2002.

VAN DER STELT, M; DI MARZO, V. Anandamide as an intracellular messenger regulating ion channel activity. Prostaglandins Other Lipid Mediators, v. 77, p. 111-122, 2005.

VAN DER STELT, M.; DI MARZO, V. Cannabinoid receptors and their role in Neuroprotection. Neuromol. Med., v. 7, p. 37-50, 2005.

VELDHUIS, W.B.; VAN DER SELT, M.; WADMAN, M.W.; VAN ZADELHOFF, G.; MACCARRONE, M.; FEZZA, F.; VELDINK, G.A.; VLIEGENTHART, J.F.; BAR, P.R.; NICOLAY, K.; DI MARZO, V. Neuroprotection by the endogenous cannabinoid anandamide and arvanil against in vivo excitotoxicity in the rat: role of vanilloid receptors and lipoxygenases. Neuroscience, v. 23, p .4127-4133, 2003. 
VENEGAS, H. Comparative neurology of the optic tectum, 1984.

WANG, X.; DOW-EDWARDS, D.; KELLER, E.; HURD, Y.L. Preferential limbic expression of the cannabinoid receptor mRNA in the human fetal brain. Neuroscience, v. 118, p. 681-694, 2003.

WANG, Y.; LUKSCH, H.; BRECHA, N.C.; KARTEN, H.J. Columnar projections from the cholinergic nucleus isthmi to the optic tectum in chicks (Gallus gallus): a possible substrate for synchronizing tectal channels. J. Comp. Neurol., v. 494, p. 7-35, 2006.

YAZULLA, S.; STUDHOLME, K.M.; MCINTOSH, H.H.; DEUTSCH, D.G. Immunocytochemical localization of cannabinoid $\mathrm{CB}_{1}$ receptors and fatty acid amide hydrolase in rat retina. J. Comp. Neurol., v. 415, p. 80-90, 1999.

YIN, H.H.; DAVIS, M.I.; RONESI, J.A.; LOVINGER, D.M. The role of protein synthesis in striatal long-term depression. J Neurosci., v. 26, p. 11811-11820, 2006.

ZANI, A.; BRAIDA, D.; CAPURRO, V.; SALA, M. Delta9-tetrahydrocannabinol (THC) and AM 404 protect against cerebral ischaemia in gerbils through a mechanism involving cannabinoid and opioid receptors. Br. J. Pharmacol., v. 152, p. 1301-1311, 2007.

ZHUANG, S.Y.; BRIDGES, D.; GRIGORENKO, E.; MCCLOUD, S.; BOON, A.; HAMPSON, R. E.; DEADWYLER, S. A. Cannabinoids produce neuroprotection by reducing intracellular calcium release from ryanodine-sensitive stores. Neuropharmacology, v. 48, p. 1086-1096, 2005. 